\title{
Pulse article: Survey on the current usage of the International Standards for the Assessment of Autonomic Function after Spinal Cord Injury (ISAFSCI)
}

\author{
Marcalee Alexander ${ }^{1,2,3} \cdot$ Jill Wecht $\mathbb{B}^{4,5} \cdot$ Andrei Krassioukov ${ }^{6,7} \cdot$ International Autonomic Standards Committee
}

Received: 24 August 2017 / Revised: 27 September 2017 / Accepted: 3 October 2017

(c) International Spinal Cord Society 2017

\begin{abstract}
Study design Online questionnaire.

Objectives To identify the awareness, and current use, of the International Standards for the Assessment of Autonomic Function after SCI (ISAFSCI) and suggest necessary revisions.

Setting An international collaboration of committee members.

Methods A survey was drafted and consensus achieved among members of the International Standards Committee of the ASIA. The questionnaire was posted on SurveyMonkey for 2 months. A survey link was posted on the ASIA and ISCoS websites, and committee members circulated the survey to colleagues with the goal of obtaining a wide-spread international response.

Results A total of 173 providers responded. About half $(n=84)$ of the respondents used the standards in some form. Fortyfour percent $(n=72)$ felt they knew the difference between the standards and the data sets. Among 135 responses on the usefulness of the ISAFSCI, the bladder, bowel, and sexual function sections, and the heart rate, respiratory rate, blood pressure, and sudomotor sections for use in patients with tetraplegia were reported as most useful. Comments revealed that respondents would like more explanation regarding specific definitions of components of the standards, how/when to use the ISAFSCI, and how the ISAFSCI may assist in clinical care.

Conclusion The ISAFSCI is used by a subset of SCI clinicians. Some find the standards useful, while others are unaware of the utility of the ISAFSCI to prevent morbidity and assist in documentation of autonomic recovery post SCI. Further clarification regarding the definition of various disorders, and how and why to use the ISAFSCI in the SCI population, is needed.
\end{abstract}

\section{Introduction}

The International Standards for Assessment of Autonomic Function after SCI (ISAFSCI) were first published in 2009 after development and consensus by an international expert committee [1]. Based on preliminary feedback, after 3 years, these standards were amended, the ISAFSCI

Marcalee Alexander

spinalcordmd@live.com

Birmingham VA Medical Center, Birmingham, AL 35233, USA

2 University of Alabama at Birmingham Department of Physical Medicine and Rehabilitation, Birmingham, AL 35294, USA

3 Harvard Medical School Department of Physical Medicine and Rehabilitation, Boston, MA 02115, USA abbreviation was coined and the revised version was disseminated via journal publication [2]. Moreover, in 2012, a booklet was created for further distribution [3]. The ISAFSCI provides a standard format to document the impact of spinal cord injury (SCI) on autonomic neural control of specific organ systems, including the following: (1) general autonomic responses related to cardiovascular,

4 National Center for the Medical Consequences of SCI: James J Peters VA Medical Center, Bronx, NY 10468, USA

5 Department of Medicine and Rehabilitation Medicine, The Icahn School of Medicine, Mount Sinai, New York, NY 10029, USA

6 International Collaboration On Repair Discoveries, Vancouver, BC V6T 1Z4, Canada

7 University of British Columbia, Vancouver, BC V6T 1Z4, Canada 
pulmonary, and sudomotor function, and (2) sacral focused responses, including bladder, bowel, and sexual function. The ISAFSCI is designed to complement the International Standards for Neurologic Classification of SCI (ISNCSCI) [4], and to provide a rapid means of dissemination among clinicians and scientists describing the specific effects of autonomic impairment following SCI on organ system function.

Similar to the ISNCSCI, the ISAFSCI were first developed as a tool to improve communication and were not subject to rigorous testing before publication and dissemination; rather they were developed based on expert opinion. Therefore, education of clinicians and researchers, and subsequent testing of the ISAFSCI for use in the clinical and research settings are of vital importance. Training to date has included the development of the Astep, an online tool that discusses autonomic function after SCI [5], and face-to-face workshops at annual meetings, where the use of the ISAFSCI to document remaining autonomic function is described and discussed in detail [6]. In addition, a recent publication reported inter-rater reliability of the ISAFSCI, which demonstrated good-strong agreement in the sacral section of the assessment and moderate agreement in the general autonomic function section [7].

In 2016, the Autonomic Standards Committee began working on an updated version of the ISAFSCI (version 3). Prior to development of the next version of the ISAFSCI, the committee sought to determine the utility of the current standards, and to ascertain whether or not the ISAFSCI is providing the most useful data possible to clinicians and researchers. As part of this process, an international survey was created to assess the opinions of clinicians and researchers in the field of SCI medicine regarding the purpose, benefit, and utility of the current form of the ISAFSCI, and to gain insight into the needs of the community to inform development of the next version.

\section{Methods}

A draft of the survey was developed by three committee members (MA, JW, and AK), and was subsequently circulated to other members for input prior to finalization and distribution. Once consensus was achieved, the survey was drafted online via SurveyMonkey and was circulated again for committee review. After agreement, the survey was posted online and all committee members were asked to distribute the survey to their respective societies and colleagues within the field of SCI medicine. The survey was open and available for response entry for a period of 2 months.

\section{Results}

\section{Survey respondents}

A total of 173 clinical providers responded to the survey; $157(91 \%)$ provided information regarding their work environment and 76 (44\%) provided the country in which they worked. The majority of responders worked in a large clinical practice $(64 \%)$ caring for over 50 patients (inpatients and/or outpatients) with SCI annually, 20\% worked in a medium-size practice (up to 50 patients annually), and $15 \%$ worked in a small practice (less than 10 patients annually). An international group of clinicians responded to the survey; $49 \%$ were from European countries, 36\% from North America, $7 \%$ from ASIA, $8 \%$ from Australasia, and 1 respondent was from Africa.

\section{Specific survey questions}

Do you use the autonomic standards in your clinical practice? Only $10 \%$ of the respondents reported that they used the ISAFSCI all of the time in their clinical practice, $18 \%$ said that they used the standards some of the time, while $49 \%$ reported that they did not use the standards at all in their clinical practice.

If you do not use the standards, why don't you? Of those who said that they did not use the standards regularly, 106 answered a question as to why: $33 \%$ reported that they did not understand the benefit of the ISAFSCI, $28 \%$ reported that they did not have time, $24 \%$ reported that they never heard of them, $8 \%$ reported that they did not know how to use them, and $7 \%$ reported that they had not been translated into their language. The responses to this question are being used to advise development of the next edition of the ISAFSCI.

If you use the standards but only part of them, which parts do you use? Of the 80 respondents who answered this question, $85 \%$ used the bladder section, $69 \%$ used the bowel section, $58 \%$ used the cardiovascular section, and $54 \%$ used the sexual function section. Only $36 \%$ used the respiratory function standards and only $20 \%$ used the sudomotor section.

Do you understand the difference between the standards and the International Data Sets? A total of 164 clinicians responded to this question, $44 \%$ said that they understood the difference between the ISAFSCI and the International Data Sets; however, $38 \%$ reported that they were not sure of the difference and $18 \%$ acknowledged that they did not understand the difference between the two tools.

Please comment on the usefulness of each of the following parts of the standards: 135 respondents answered this question (Table 1). In general, the ISAFSCI appeared to be more useful to clinicians when assessing cardiovascular, 
Table 1 Clinicians's Perceived Utility of Components of the International Standards to Assess Autonomic Function Post SCI

\begin{tabular}{|c|c|c|c|c|}
\hline Component/N & $\begin{array}{l}\text { Very Useful } \\
(\% / n)\end{array}$ & $\begin{array}{l}\text { Somewhat Useful } \\
(\% / n)\end{array}$ & Neutral $(\% / \mathrm{n})$ & $\begin{array}{l}\text { Not Useful } \\
(\% / n)\end{array}$ \\
\hline \multirow[t]{2}{*}{ Heart Rate-Tetraplegia/132 } & $47.0 \%$ & $26.5 \%$ & $23.5 \%$ & $3.0 \%$ \\
\hline & 63 & 35 & 31 & 4 \\
\hline \multirow[t]{2}{*}{ Heart Rate-Paraplegia/132 } & $18.9 \%$ & $40.9 \%$ & $34.1 \%$ & $6.1 \%$ \\
\hline & 25 & 54 & 45 & 8 \\
\hline \multirow[t]{2}{*}{ Blood Pressure-Tetraplegia/131 } & $58.0 \%$ & $21.4 \%$ & $16.0 \%$ & $4.6 \%$ \\
\hline & 76 & 28 & 21 & 6 \\
\hline \multirow[t]{2}{*}{ Blood Pressure-Paraplegia/131 } & $30.5 \%$ & $36.6 \%$ & $28.2 \%$ & $4.6 \%$ \\
\hline & 40 & 48 & 37 & 6 \\
\hline \multirow[t]{2}{*}{ Respiratory-Tetraplegia/129 } & $51.2 \%$ & $24.0 \%$ & $19.4 \%$ & $5.4 \%$ \\
\hline & 66 & 31 & 25 & 7 \\
\hline \multirow[t]{2}{*}{ Respiratory-Paraplegia/128 } & $18.8 \%$ & $39.1 \%$ & $35.9 \%$ & $6.3 \%$ \\
\hline & 24 & 50 & 46 & 8 \\
\hline \multirow[t]{2}{*}{ Sudomotor-Tetraplegia/125 } & $40.0 \%$ & $20.8 \%$ & $32.0 \%$ & $7.2 \%$ \\
\hline & 50 & 26 & 40 & 9 \\
\hline \multirow[t]{2}{*}{ Sudomotor-Paraplegia/125 } & $21.6 \%$ & $28.8 \%$ & $40.0 \%$ & $9.6 \%$ \\
\hline & 27 & 36 & 50 & 12 \\
\hline \multirow[t]{2}{*}{ Bladder-Tetraplegia/133 } & $62.4 \%$ & $15.8 \%$ & $17.3 \%$ & $4.5 \%$ \\
\hline & 83 & 21 & 23 & 6 \\
\hline \multirow[t]{2}{*}{ Bladder-Paraplegia/133 } & $58.7 \%$ & $20.3 \%$ & $16.5 \%$ & $4.5 \%$ \\
\hline & 78 & 27 & 22 & 6 \\
\hline \multirow[t]{2}{*}{ Bowel-Tetraplegia/131 } & $53.4 \%$ & $22.1 \%$ & $18.3 \%$ & $6.1 \%$ \\
\hline & 70 & 29 & 24 & 8 \\
\hline \multirow[t]{2}{*}{ Bowel-Paraplegia/132 } & $53.0 \%$ & $22.7 \%$ & $18.9 \%$ & $5.3 \%$ \\
\hline & 78 & 30 & 25 & 7 \\
\hline \multirow[t]{2}{*}{ Sexual Function-Tetraplegia/133 } & $51.1 \%$ & $21.8 \%$ & $23.3 \%$ & $3.8 \%$ \\
\hline & 68 & 29 & 31 & 5 \\
\hline \multirow[t]{2}{*}{ Sexual Function-Paraplegia/133 } & $52.6 \%$ & $22.6 \%$ & $21.1 \%$ & $3.8 \%$ \\
\hline & 70 & 30 & 28 & 5 \\
\hline
\end{tabular}

respiratory, and sudomotor function in a patient with tetraplegia than paraplegia; however, the usefulness of the ISAFSCI did not differ by lesion level for sacral autonomic function.

Would you be more likely to use the standards if they were part of the International Standards for the Neurologic Classification of SCI? With regard to further use of the standards, $68 \%$ of respondents indicated that they would be more likely to use the standards if they were part of the ISNCSCI, 24\% reported that they were not sure if combining the two classification scales would improve ISAFSCI usage, and $9 \%$ indicated that they would not be more likely to use the ISAFSCI if it were coupled with the ISNCSCI.

Would it be helpful if the autonomic standards provided the likely impact of the specific injury on autonomic function? e.g. With T6 AIS A injury, would it be helpful if the standards document suggests the likely effect of the SCI on bladder, bowel and sexual function (BBS) and autonomic dysreflexia $(A D)$ ? Respondents were queried about whether it would be helpful if the ISAFSCI included the likely impact of a specific injury level on autonomic function to each organ system. The vast majority of respondents, i.e. $74 \%$ (121), said yes, whereas only $19 \%$ (32) said not sure, and $6 \%$ (10) said no.

What are your recommendations regarding future changes to the ISAFSCI? These suggestions are shown in Table 2. While some individuals noted no changes needed, others requested simplification. More detailed explanation and education regarding use of the ISAFSCI was requested, as was combining the ISAFSCI with the INCSCI. Finally, the development of an app and the need to link the standards with clinical interventions and research were suggested.

\section{Discussion}

This survey has addressed the current use, perceived usefulness, and recommendations for modification to the 
Table 2 Suggestions for changes to the International Standards to assess Autonomic Function after SCI

Reasons for usage

Provides a clinical guide non-SCI clinicians

Assist with staff training

Improves patient care

Addresses an important clinical concern

Increases clinical awareness

Reasons for non-usage

$$
\begin{aligned}
& \text { Unclear benefit } \\
& \text { Too time consuming } \\
& \text { Has not been validated } \\
& \text { Difficult to use } \\
& \text { Lack thorough usage instruction } \\
& \text { Unrelated to clinical practice } \\
& \text { Insurance does not cover } \\
& \text { Unfamiliar with the document }
\end{aligned}
$$

Suggested Revisions

Should be simplified
Combine with ISNCSCI exam
Document how to use to evaluate change
with time/intervention
Test accuracy in clinical trial
Provide more detailed definitions
Explanation of scoring system
Provide an on-line form
Provide normative data
Provide template questions with likely
responses

current edition of the ISAFSCI. The survey results revealed the need to further educate clinical healthcare providers, not only about the purpose of the ISAFSCI, but also regarding the importance of assessing and communicating in more detail the impact of SCI on autonomic nervous system control of organ system function. While providers are knowledgeable regarding recovery of neurologic function pertaining to the somatic nervous system, we appreciate that this, in large measure, has to do with the 30-year history of the ISNCSCI, which has naturally led to improvements in understanding the examination, efficacy of performing the examination, and widespread usage. We anticipate a similar long-term trajectory with the development and future progressive adaptation of the ISAFSCI. Our study is limited as it was internet-based and subject to response bias. It is possible that only physicians who were interested and aware of the topic responded. Additionally, we had a relatively low number of respondents. Nevertheless, we believe that the results warrant discussion and response.

The ISAFSCI (version 1) [1] provided the international community of SCI clinicians a means of documenting and sharing information pertaining to the effect of SCI level on sacral function and on general autonomic function in a onepage form. This was a practical tool, requiring continuous modification and refinement akin to that which occurred with removal of the urodynamic section of the ISAFSCI in 2012 (version 2) [2]. In our survey, the majority of respondents confirmed that the ISAFSCI was useful, particularly in patients with tetraplegia; however, many participants also indicated the need for further education regarding the benefits of ISAFSCI, the specific impacts of injury level on expected autonomic responses, the impact of autonomic impairment on organ system function, the potential for autonomic recovery, and implication on overall health and longevity.

The inter-rater reliability of the ISAFSCI was recently reported [7]. Evidence suggests good-strong inter-day reliability (10-14 days) for the sacral assessments, and moderate reliability for general autonomic function. In light of this, use of these ISAFSCI in conjunction with the ISNCSCI could serve as a foundation when documenting the anticipated impact of level and completeness of injury on sacral autonomic responses, and may also be used to determine the potential for recovery of bladder, bowel, and sexual function. Similar to recovery of ambulatory function based on motor score from the ISNCSCI [8], the degree of remaining supraspinal control of sacral autonomic function as determined from the ISAFSCI may be predictive of recovery of bladder, bowel, and sexual function. With regard to motor function, it is appreciated that persons with SCI do not go from being completely paralyzed to achieving normal ambulation. Similarly, individuals with SCI with some bladder or bowel control are likely to regain volitional continence as compared to individuals without any sensation or control. Unfortunately, although continence is important to individuals after SCI [9], regaining independent control of bladder and bowel function, without medications or devices, is minimally addressed during rehabilitation and inadequately addressed with the current ISNCSCI [10]. Additionally, retention of orgasmic capacity has been linked to the preservation of the bulbocavernosus reflex, yet this is not tested or addressed as part of the ISNCSCI [11,12]. Instead, the sacral components of the ISNCSCI are generally studied to provide more accurate ways to predict recovery of ambulatory function after SCI [13]. Based on the specific components that constitute the sacral section, the ISAFSCI provides a template for documenting the potential for regaining neurologic control of bladder, bowel, and sexual function. Of importance, the ISAFSCI could be used to guide clinicians in selecting patients with the potential for further recovery of control of bladder, bowel, and sexual responses.

The ISAFSCI also provides an ability to document the impact of injury on general autonomic responses. Our 
survey highlights the high utility and usefulness of the ISAFSCI for use in patients with tetraplegia. The issues of autonomic dysreflexia, orthostatic hypotension, and thermoregulatory dysfunction are important concerns for persons with SCI and can have a devastating impact on quality of life. Documenting the degree of these health concerns in a concise format, such as described in the ISAFSCI, will serve to emphasize the need to address the cardiovascular, thermoregulatory, and respiratory aspects of autonomic function after SCI in clinical settings. Although use of the ISAFSCI in individuals with acute SCI during inpatient rehabilitation within a tertiary rehabilitation center was low compared to use of the ISNCSCI, blood pressure problems were among the most commonly reported general autonomic disorders, while sacral dysfunction was noted in almost all patients [14]. Appropriate use of the ISAFSCI has the potential to guide clinical care and eliminate unnecessary testing, thereby lowering the costs of inpatient rehabilitation and decreasing morbidity and mortality in patients with acute SCI.

The results of this survey suggest the need for the ISAFSCI to provide information regarding the probable impact of injury level on specific autonomic responses, rather than just querying the patient regarding these functions. It follows that this may assist the provider in determining which deficits can and cannot be attributed to the SCI. For instance, if an individual with a T12 injury is suffering from extreme hypertension and headache, the clinician should be looking for other causes of hypertension rather than $\mathrm{AD}$; or when a young person with a high level of paraplegia is unable to have reflex erections this is unlikely to be due to the SCI, rather the clinician should review iatrogenic concerns or other confounding factors. Thus, by providing an understanding of the anticipated impact of level and severity of injury on autonomic/organ system function, the ISAFSCI can guide clinical decision-making and improve the overall care of individuals with SCI. This is not to say that the ISAFSCI should be the sole guide to clinical decision-making; however, the tool can be used to guide the clinician as to what the likely autonomic changes related to the SCI are.

Suggested revisions to the ISAFSCI are similar to those of Round et al. [6] who commented on the need for less ambiguity. Additional recommendations from respondents regarding revision to the ISAFSCI include both simplification and the addition of more detail. Similar to the ISNCSCI, the ISAFSCI may evolve into both a detailed and a simplified format. Regardless of which recommendations are brought forth in version 3 of the ISAFSCI, the purpose of the standards will remain the same: (1) to provide a consistent format for documentation of the impact of SCI on autonomic function and (2) to increase awareness of the impact of SCI on autonomic/organ system function. It should be appreciated that the ISAFSCI, which was initially introduced in 2009, is still a relatively novel tool that is evolving, and that at present only a limited number of clinicians use the tool on a regular basis. The limited number of publications on use of the ISAFSCI suggests that although there is apparent appreciation regarding the usefulness of the tool, clinical adherence to the standards is low [13]. Hands-on educational workshops that aim to improve the use and utility of the ISAFSCI may be effective in disseminating information to providers and will continue to be a useful tool for future training [14].

Acknowledgements We would like to acknowledge the American Spinal Injury Association and the International Spinal Cord Society for their financial and organizational support, and Fin Biering-Sørensen, Stacy Elliot, Michael Kennelly, Klaus Krogh, and Mehnert Ulrich for their expertise and scientific contribution to the development of the ISAFSCI survey.

\section{Compliance with ethical standards}

Conflict of interest The authors declare that they have no conflict of interest.

\section{References}

1. Alexander MS, Biering-Sorensen F, Bodner D, Brackett NL, Cardenas, Charlifue $\mathrm{S}$, et al. International standards to document remaining autonomic function after spinal cord injury. Spinal Cord. 2009;47:36-43.

2. Krassioukov A, Biering-Sorensen F, Donovan W, Kennelly M, Kirshblum S, Krogh K, et al. International standards to document remaining autonomic function after spinal cord injury. J Spinal Cord Med. 2012;35:201-10.

3. American Spinal Injury Association. International Standards to document remaining autonomic function after spinal cord injury. Atlanta, GA; 2012.

4. Kirshblum SC, Burns SP, Biering-Sorensen F, Donovan W, Graves DE, Jha A, et al. International standards for neurological classification of spinal cord injury (revised 2011). . J Spinal Cord Med. 2011;34:535-46.

5. American Spinal Injury Association. ASIA Learning Center. 2017. http://www.asiaspinalinjury.org/elearning/elearning.php. Accessed on 6 July 2017.

6. Round AM, Park SE, Walden K, Noonan VK, Townson AF, Krassioukov AV. An evaluation of the International Standards to document remaining Autonomic Function after Spinal Cord Injury: input from the international community. Spinal Cord. 2017;55:198-203.

7. Davidson R, Carlson M, Fallah N, Noonan V, Elliott S, Joseph J, et al. Inter-rater reliability of the International Standards to document Autonomic Function after SCI: ISAFSCI. J Neurotrauma. 2017;34:552-8.

8. Field-Fote EC, Yang JF, Basso DM, Gorrasini M. Supraspinal control predicts locomotor function and forecasts responsiveness to training after spinal cord injury. $\mathbf{J}$ Neurotrauma. 2017;34:1813-25.

9. Anderson K. Targeting recovery: Priorities of the spinal cord injury population. J Neurotrauma. 2004;21:1371-83.

10. Alexander MS, Conley C, Chen Y, McLain A. The use of the neurologic exam to predict awareness and control of lower urinary 
tract function post SCI. Spinal Cord. 2017;55:795; https://doi.org/ 10.1038/sc.2017.55.

11. Sipski ML, Alexander CJ, Gomez-Marin O. Effects of level and degree of spinal cord injury on male orgasm. Spinal Cord. 2006;44:798-804.

12. Sipski ML, Alexander CJ, Rosen R. Sexual arousal and orgasm in women: effects of spinal cord injury. Ann Neurol. 2001;49:35-44.
13. Marino RM, Schmidt-Read M, Kirshblum S, Dyson-Hudson TA, Tansey K, Morse LR, et al. Reliability and validity of S3 pressure sensation as an alternative to deep anal pressure in neurologic classification of persons with spinal cord injury. Arch Phys Med Rehabil. 2016;97:1642-6.

14. Squair JW, le NG, Noonan VK, Raina G, Krassioukov AV. Assessment of clinical adherence to the international autonomic standards following spinal cord injury. Spinal Cord. 2015;53:668-72. 